\title{
Production of ergothioneine by Methylobacterium species
}

\author{
Kabir M. Alamgir ${ }^{1}$, Sachiko Masuda ${ }^{1,2}$, Yoshiko Fujitani ${ }^{1}$, Fumio Fukuda ${ }^{3}$ and Akio Tani ${ }^{1 *}$ \\ ${ }^{1}$ Group of Plant-Microbe Interactions, Institute of Plant Science and Resources, Okayama University, Okayama, Japan, \\ ${ }^{2}$ Advanced Low Carbon Technology Research and Development Program, Japan Science and Technology Agency, Tokyo, \\ Japan, ${ }^{3}$ Laboratory of Pomology, Graduate School of Environmental and Life Science, Okayama University, Okayama, Japan
}

Metabolomic analysis revealed that Methylobacterium cells accumulate a large amount of ergothioneine (EGT), which is a sulfur-containing, non-proteinogenic, antioxidative amino acid derived from histidine. EGT biosynthesis and its role in methylotrophy and physiology for plant surface-symbiotic Methylobacterium species were investigated in this study. Almost all Methylobacterium type strains can synthesize EGT. We selected one of the most productive strains ( $M$. aquaticum strain 22A isolated from a moss), and investigated the feasibility of fermentative EGT production through optimization of the culture condition. Methanol as a carbon source served as the best substrate for production. The productivity reached up to $1000 \mu \mathrm{g} / 100 \mathrm{ml}$ culture $(1200 \mu \mathrm{g} / \mathrm{g}$ wet weight cells, $6.3 \mathrm{mg} / \mathrm{g}$ dry weight) in 38 days. Next, we identified the genes (egtBD) responsible for EGT synthesis, and generated a deletion mutant defective in EGT production. Compared to the wild type, the mutant showed better growth on methanol and on the plant surface as well as severe susceptibility to heat treatment and irradiation of ultraviolet (UV) and sunlight. These results suggested that EGT is not involved in methylotrophy, but is involved in their phyllospheric lifestyle fitness of the genus in natural conditions.

Keywords: ergothioneine, methylotroph, methanol, Methylobacterium species, glutathione, reactive oxygen species, antioxidant

\section{INTRODUCTION}

Methylobacterium species are facultative methylotrophic bacteria that can use both methanol and multi-carbon substances. They are ubiquitous in nature, and metagenomic studies on some plant species (Knief et al., 2011) and rice (Delmotte et al., 2009) showed their predomination on plant surfaces (the phyllosphere). This is believed to occur because plants emit methanol as a by-product of pectin demethylation (Fall and Benson, 1996; Jourand et al., 2005). Since global leaf area is estimated to be ca. $6.4 \times 10^{8} \mathrm{~km}^{2}$ (Morris and Kinkel, 2002) and global emission of plant methanol is estimated to be $10^{14}$ grams per year (Guenther et al., 1995), the interaction between plants and Methylobacterium species is of importance to consider plant health, agriculture, and the global cycle of one-carbon compounds as well. In addition to the abundant and extensive study on their methylotrophic metabolism (Vuilleumier et al., 2009), their physiology in the phyllosphere has been gathering a great deal of attention (Gourion et al., 2006), since the phyllosphere is considered to be a harsh environment, in which microorganisms are exposed to UV, temperature shifts, fluctuations in water availability, and limited resources for growth (Vorholt, 2012). Methylobacterium species have been reported to be able to promote plant growth 
(Abanda-Nkpwatt et al., 2006; Tani et al., 2012) due to their ability to synthesize phytohormones (Ivanova et al., 2000; Koenig et al., 2002; Schauer and Kutschera, 2011) and 1-aminocyclopropane 1-carboxylate deaminase, which decreases the ethylene level in plants (Madhaiyan et al., 2006, 2007; Chinnadurai et al., 2009).

The microbial synthesis of low-value products as well as fine chemical compounds using methylotrophs has also been documented. Methanol is a cheap, non-food feedstock that is easily generated from diverse renewable sources such as biogas and synthesis gas. These gases can be derived from methane, which is also abundant and inexpensive. Thus, methanol is a more attractive and advantageous feedstock than sugars and their polymers. In addition, developments in fermentation technology (Bourque et al., 1995; Bélanger et al., 2004) as well as the accumulated knowledge on metabolic pathways (Šmejkalová et al., 2010; Chistoserdova, 2011) have been rendering methylotrophic bacteria as attractive catalysts to synthesize fine chemicals. The production of amino acids and polyhydroxyalkanoates as well as high biomass yield from methanol has been reviewed by Schrader et al. (2009).

In our previous report, we isolated $M$. aquaticum strain 22A from a hydroponic culture sample of a moss, Racomitrium japonicum (Tani et al., 2012). We have been using the strain as a model for Methylobacterium-plant interaction with respect to plant-growth promotion. We found that strain $22 \mathrm{~A}$ cells highly accumulate ergothioneine (EGT) through metabolome analysis in this study. EGT is a sulfur-containing, non-proteinogenic amino acid derived from histidine. It was first discovered in ergot fungi and its structure was determined in 1911 (Mann and Leone, 1953). The compound is believed to be synthesized in few organisms, notably actinobacteria, cyanobacteria, and certain fungi (Fahey, 2001; Pfeiffer et al., 2011). The genes for EGT synthesis were first described for Mycobacterium species (Seebeck, 2010). The clustered egtABCDE genes were shown to encode proteins that convert histidine to EGT. EgtD is a methyltransferase that converts histidine to hercynine. EgtB, an FGE (formylglycine generating enzyme)like protein, conjugates $\gamma$-glutamylcysteine to hercynine to form $\gamma$-glutamylcysteinylhercynine. EgtC, a glutamine amidotransferase, releases glutamate from it to generate $S$ - $(\beta$-amino- $\beta$-carboxyethyl)ergothioneine sulfoxide. EgtE, pyridoxal 5-phosphate dependent $\beta$-lyase, forms EGT. EgtA $(\gamma$-glutamylcysteine synthetase) supplies $\gamma$-glutamylcysteine for EgtB. Homologous genes for egt $B$ and egtD were found in many eukaryotes and bacteria, including Methylobacterium species. The other genes have also been detected in many eukaryotes (Jones et al., 2014). Thus, EGT synthesis in Methylobacterium species has been predicted, but its productivity and its role in methylotrophy and physiology have not hitherto been investigated.

EGT has been reported to be an important component of cells because of its antioxidant properties (Cheah and Halliwell, 2012). In humans, EGT has been shown to accumulate in various cells and tissues at high concentrations $(100 \mu \mathrm{M}-$ $2 \mathrm{mM}$ ), although human cells do not produce EGT (Cheah and Halliwell, 2012). EGT is concentrated in mammalian mitochondria, suggesting a functional role in protecting it from mitochondrial superoxide (Paul and Snyder, 2010). EGT is known to absorb ultraviolet (UV) light, which may account for the ability to block UV damage (Bazela et al., 2014). Importantly, in mammalian cells, the EGT transporter ETT/OCTN1 was identified (Gründemann et al., 2005; Grigat et al., 2007), suggesting that EGT is preferentially acquired by the cells. Certain species of mushrooms are distinguished sources of EGT, ranging from 0.4 to $2.0 \mathrm{mg} / \mathrm{g}$ (Ito et al., 2011) or 0.08 to $3.78 \mathrm{mg} / \mathrm{g}$ (Dubost et al., 2006) in dry weight. In Mycobacterium smegmatis, intracellular and extracellular EGT of 4.1 and $17 \mathrm{pg} / 10^{5}$ colony-forming units (CFUs), respectively, was reported (Sao Emani et al., 2013). An overproduction system from the fission yeast Schizosaccharomyces pombe was constructed, resulting in 5000-fold higher productivity of $1600 \mu \mathrm{M}$ in intracellular concentration (Pluskal et al., 2014). In cyanobacteria, $0.8 \mathrm{mg} / \mathrm{g}$ dry mass was reported (Pfeiffer et al., 2011).

In this study, we revealed the abundant EGT accumulation in Methylobacterium species for the first time and investigated the feasibility of fermentative EGT production from methanol using M. aquaticum strain 22A. Furthermore, we report the phenotype of a mutant deficient for EGT production, and suggest its important role in the phyllospheric lifestyle of the genus.

\section{MATERIALS AND METHODS}

\section{Microbial Strain and Culture Condition}

Mineral medium (MM) composition is presented in Table S1. Different concentrations of methanol, succinate, glucose, or ethanol were used as carbon sources. R2A, Luria-Bertani (LB), and Middlebrook 7H9 (a mineral medium for Mycobacterium species containing sodium citrate and glutamic acid as carbon sources, on which Methylobacterium species grow well when methanol is supplemented) (Middlebrook and Cohn, 1958) were also tested. Kanamycin $(25 \mu \mathrm{g} / \mathrm{mL})$ was used when necessary. Methylobacterium species were cultivated at $28^{\circ} \mathrm{C}$. Escherichia coli strains were grown in $\mathrm{LB}$ at $37^{\circ} \mathrm{C}$.

A rifampicin-resistant spontaneous mutant of strain $22 \mathrm{~A}$ (22A-rif) was obtained by streaking wild type on R2A agar containing $2 \mu \mathrm{g} / \mathrm{ml}$ rifampicin; its growth on methanol was confirmed to be normal. The frequency of spontaneous mutation was estimated to be $10^{-7}$. mTn5gusA-pgfp22 (Xi et al., 1999) was used to derive the GFP-expressing kanamycin-resistant strain.

\section{Metabolome Analysis with Capillary Electrophoresis Time-of-Flight Mass Spectrometry (CE-TOF/MS)}

The cells of strain $22 \mathrm{~A}\left(1.45 \times 10^{9}\right.$ cells $)$ grown in liquid MM containing $0.5 \%$ methanol for 3 days were harvested, filter-trapped with a $0.4 \mu \mathrm{m}$ pore membrane (millipore), and rinsed with water. The cells were transferred into $2 \mathrm{ml}$ of methanol containing $5 \mu \mathrm{M}$ methionine sulfone and camphor10-sulfonic acid. The samples were sent to Human Metabolome Technologies Inc. (HMT, Tsuruoka, Japan). A total of $1.6 \mathrm{ml}$ of 
chloroform and $640 \mu \mathrm{l}$ of water were added to the sample. The sample was then vortexed and centrifuged at $2300 \times \mathrm{g}$, at $4^{\circ} \mathrm{C}$ for $5 \mathrm{~min}$. The water layer was taken and filtered by an Ultrafree$\mathrm{MC}, 5 \mathrm{kDa}$ (molecular weight) cut-off centrifugal filter device (HMT) to remove proteins. The filtrate was dried, dissolved in $25 \mu \mathrm{l}$ of ultra-pure water, and then analyzed using CE-TOF/MS equipped with an Agilent 6210 TOF/MS (Agilent Technologies, Waldbronn, Germany). Cationic metabolites were analyzed with a fused silica capillary $(50 \mu \mathrm{m}$ inner diameter $\times 80 \mathrm{~cm}$ total length) with a commercial cation electrophoresis buffer (Solution H3301-1001, HMT) as the electrolyte. The sample was injected at a pressure of $50 \mathrm{mbar}$ for $10 \mathrm{~s}$ (approximately $10 \mathrm{nl}$ ). The applied voltage was set at $27 \mathrm{kV}$. Electrospray ionization-mass spectrometry was conducted in the positive ion mode, and the capillary voltage was set at $4 \mathrm{kV}$. The spectrometer was scanned from 50 to $1000 \mathrm{~m} / \mathrm{z}$ (mass-to-charge ratio). Other conditions were the same as those in the cation analysis described previously (Soga et al., 2003). In the same way, anionic metabolites were analyzed with a commercial anion electrophoresis buffer (Solution H3302-1021, HMT). The sample was injected at a pressure of $50 \mathrm{mbar}$ for $25 \mathrm{~s}$ (approximately $25 \mathrm{nl}$ ). The applied voltage was set at $30 \mathrm{kV}$. Electrospray ionization-mass spectrometry was conducted in the negative ion mode, and the capillary voltage was set at $3.5 \mathrm{kV}$. The spectrometer was scanned from 50 to $1000 \mathrm{~m} / \mathrm{z}$. Other conditions were as in the anion analysis (Soga et al., 2003).

\section{EGT and Glutathione Quantification}

The cells of strain 22A grown in liquid media were harvested by centrifugation $\left(12,000 \times \mathrm{g}, 25^{\circ} \mathrm{C}, 10 \mathrm{~min}\right)$ and washed with $0.85 \% \mathrm{NaCl}$. The wet weight of the cells was recorded. Dry weight was obtained by complete drying of the cells at $100^{\circ} \mathrm{C}$ when necessary. The intracellular EGT was extracted by heating the cell suspension in water at $94^{\circ} \mathrm{C}$ for $10 \mathrm{~min}$. The cell suspensions were vortexed at $1600 \mathrm{rpm}$ for $30 \mathrm{~min}$ and centrifuged $(14,000 \times$ $\left.\mathrm{g}, 25^{\circ} \mathrm{C}, 10 \mathrm{~min}\right)$ to remove cells. The supernatants were filtered $(0.2 \mu \mathrm{m})$ and subjected to EGT quantification using a high performance liquid chromatography (HPLC). For extraction of glutathione, $600 \mu \mathrm{l}$ of methanol was added to the $400 \mu \mathrm{l}$ cell suspension. After mixing, $1 \mathrm{ml}$ of chloroform was added. The sample was sonicated in a sonic bath for $1 \mathrm{~min}$. A water layer of $1 \mathrm{ml}$ was taken and subjected to HPLC analysis.

EGT was quantified by an HPLC equipped with an Asahipak NH2P-50 column $(4.6 \mathrm{~mm}$ i.d. $\times 250 \mathrm{~mm}$, Asahi Kasei Co.) attached with a guard column NH2P-50G, in the following conditions: injection volume, $20 \mu \mathrm{l}$; flow rate, $0.5 \mathrm{ml} / \mathrm{min}$; detection, UV absorbance at $254 \mathrm{~nm}$. Solvent A ( $50 \mathrm{mM}$ sodium phosphate buffer containing $0.1 \%$ triethylamine, $\mathrm{pH}$ : 7.3 ) and solvent $\mathrm{B}(100 \mathrm{mM} \mathrm{NaCl})$ were used to make a gradient: $0-7 \mathrm{~min}$, $0 \% \mathrm{~B}, 7-8 \mathrm{~min}$ to $20 \% \mathrm{~B}, 8-13 \mathrm{~min} 20 \% \mathrm{~B}$, and $13-15 \mathrm{~min}$ to $0 \%$ B. EGT is eluted at around $6.1 \mathrm{~min}$.

Glutathione was quantified with the same instrument equipped with a reverse-phase $\mu$-BONDAPAK C18 column ( $4.6 \mathrm{~mm}$ i.d. $\times 250 \mathrm{~mm}$, Waters Co.) attached with a guard column (Inertsil WP300 C18 GL Science). Solvent A $(0.1 \%$ trifluoroacetic acid) and solvent B (100\% acetonitrile) were used in the isocratic solvent system of $30 \%$ solvent $\mathrm{A}$ at a constant flow rate of $0.75 \mathrm{ml} / \mathrm{min}$. Glutathione was detected by UV absorbance at $210 \mathrm{~nm}$, and was eluted at around $6.1 \mathrm{~min}$ (reduced form) and 6.6 min (oxidized form).

\section{Total Amino Acid Analysis}

Strain 22A culture grown in $100 \mathrm{ml}$ MM containing $0.5 \%$ methanol for 7 days was separated into two fractions (10 and $90 \mathrm{ml}$ ). The former was used for EGT quantification as described above. The latter was used for total amino acid extraction. Cells were collected by centrifugation, and the methanol extract $(2 \mathrm{ml})$ of the cells was dried in vacuo and dissolved in water ( $5 \mathrm{ml})$. The sample was applied to Amberlite CR1310NA ( $4 \mathrm{ml}$ resin, pre-equilibrated with successive $1 \mathrm{M} \mathrm{NaOH}$, water, $1 \mathrm{M}$ $\mathrm{HCl}$, and water). The resin was rinsed with water $(50 \mathrm{ml})$, and amino acids were eluted by $2 \mathrm{M}$ ammonia $(40 \mathrm{ml})$. The eluent was dried in vacuo and dissolved in $5 \mathrm{ml}$ water; $40 \mu \mathrm{l}$ of the sample was analyzed using an amino acid analyzer (Hitachi L-8500B). Authentic EGT could not be quantified since the analysis depends on the ninhydrin reaction in the amino group of amino acids (the amino group is trimethylated in EGT).

\section{Generation of EGT Mutant and Complemented Strains}

Using the amino acid sequences of the egt genes of Mycobacterium species (Seebeck, 2010), egt gene homologs in the strain 22A genome (Tani et al., 2015) were found by basic local alignment search tool (BLAST) analysis. While egt $A, C$, and $E$ are separately encoded in different loci, egtB and egtD are encoded in tandem in the strain 22A genome and they were subjected to deletion mutagenesis. Each kilobase of the upstream and downstream flanking regions of the egtBD genes was amplified using primers ( $5^{\prime}$ flanking sequence amplification; egtB_left_fw, tcgagctcggtacccatagagcaggctacgctgga and egtB_left_rv, catcggat cttccctcatgcg: $3^{\prime}$ flanking sequence amplification; egtD_right_fw, cgcatgagggaagatccgatcgtccaccatccggcggcactga and egtD_right_rv, ctctagaggatcccoggtcgagctccatctccag). The fragments were tandemly cloned into the Sma I site in pK18mobSacB (Schäfer et al., 1994), using the In-Fusion cloning kit (Takara Bio Co.), yielding pK18mob-egtBD. Introduction of the plasmid into strain $22 \mathrm{~A}$ was done via conjugation using E. coli S17-1. The kanamycin-resistant single-crossover mutant was streaked on R2A medium containing $10 \%$ sucrose to deliver doublecrossover mutants $(\Delta e g t)$, which were examined by diagnostic polymerase chain reaction (PCR). $\Delta \operatorname{egt}(\mathrm{mTn} 5 g u s A-p g f p 22)$ was generated by introducing mTn5gusA-pgfp22 into $\Delta e g t$, and its growth on methanol was confirmed to be normal.

For complementation of the mutation, the PCR fragment amplified from the wild-type genome with egtB_left_fw and egtD_right_rv, which contains functional egt $B D$, was cloned into $\mathrm{pK} 18 \mathrm{mobSacB}$. The resultant plasmid was introduced into $\Delta$ egt. Kanamycin-resistant colonies were selected for PCR diagnosis. The complemented strain was designated as $\Delta$ egtComp. The same plasmid was also introduced into the wild type, and the kanamycin-resistant strain was designated as WTegtDup. 


\section{Phenotypic Assays for $\Delta$ egt}

Strain $22 \mathrm{~A}$ wild type and $\Delta e g t$ were grown in MM containing $0.5 \%$ methanol to the exponential growth phase. The cells were harvested by centrifugation and washed with fresh media to make a cell suspension of OD600 $=0.5$. The cell suspension was used for the following assays, as described previously (Iguchi et al., 2013) with some modifications. (1) Heat shock resistance assay. Cells were spread on $\mathrm{R} 2 \mathrm{~A}$ agar plates for CFU determination after incubation of the cell suspension $(100 \mu \mathrm{l})$ at $46^{\circ} \mathrm{C}$ for $5,10,15$, and $20 \mathrm{~min}$. (2) $U V$ resistance assay. Cell suspensions $(100 \mu \mathrm{l})$ were exposed to $253 \mathrm{~nm}$ UV light (GL-15, Toshiba Co.) for $2 \mathrm{~min}$ (distance $20 \mathrm{~cm}$, equivalent to $800 \mu \mathrm{W} / \mathrm{cm}^{2}$ ), and then diluted and spread on R2A agar plates for CFU determination. (3) Sunlight resistance assay. Methanol-grown cells of ca. $200 \mathrm{CFU}$ were spread on solid MM containing $0.5 \%$ methanol prepared in a glass dish. The plates were covered with a glass lid or wrapped with cellophane (thickness, $0.03 \mathrm{~mm}$ ). The plates were placed on ice and exposed to sunlight at midday (done at IPSR Okayama University on Aug 18,$2015 ; 12: 00$ to $15: 00$; weather, sunny; air temperature, $33^{\circ} \mathrm{C}$; photon flux, $1500 \mu \mathrm{mol} \mathrm{s} \mathrm{m}^{-2}$, measured with a quantum sensor, UIZ-PAR-LR, Uizin Co. Japan). After 0 and $3 \mathrm{~h}$ of exposure the plates were transferred into an incubator at $28^{\circ} \mathrm{C}$ in dark. The temperature of the plates did not exceed $26^{\circ} \mathrm{C}$ during the exposure. The colonies formed on the plates were counted after 7 days cultivation. (4) Disk diffusion assay. A cell suspension in $0.75 \%$ agar was overlaid on solid MM containing $0.5 \%$ methanol and $2 \%$ agar. Aliquots $(5 \mu \mathrm{l})$ of $1 \mathrm{M} \mathrm{H}_{2} \mathrm{O}_{2}$, $2 \%$ methylglyoxal, or $1 \mathrm{M}$ diamide were deposited on filter disks placed at the center of each plate. The diameter of the growth inhibition zone was measured. Student's $t$-test was used to evaluate the statistical significance of the differences in the bacterial counts.

\section{Growth of $\Delta$ egt on Methanol}

Strain $22 \mathrm{~A}$ and $\Delta e g t$ were cultured in 96-well plates containing $200 \mu \mathrm{l}$ of MM containing methanol. The plates were incubated at $28^{\circ} \mathrm{C}$ without shaking. The cell growth (OD600) was measured using a microplate reader (Powerscan HT, DS Pharma Biomedical).

\section{In planta Competition Experiment}

Sterile seeds of Arabidopsis thaliana Col-0 were placed on 1/2 Murashige-Skoog (1/2MS) agar medium containing 3\% sucrose, $0.5 \%(\mathrm{v} / \mathrm{v}) \mathrm{MS}(5)$ vitamin, and $0.8 \%$ agar (Ina Food industry, Co.), $\mathrm{pH}$ 5.6, prepared in plastic petri dishes. The rifampicin-resistant strain 22A-rif and kanamycin-resistant $\Delta e g t(m T n 5 g u s A-p g f p 22)$ were inoculated onto the seeds. In the case of single inoculation, the inoculated cell suspension was $5 \mu \mathrm{l}$ per seed, containing ca. 20,000 CFUs. For the competitive condition, a mixture of $2.5 \mu \mathrm{l}$ of each suspension was inoculated. The plants were grown at $23^{\circ} \mathrm{C}$ under $16-/ 8$-h light/dark conditions for 27 days. The shoots were excised and put in $500 \mu \mathrm{l}$ water, and homogenized with pestles. The resultant suspension was spread onto selective R2A media containing kanamycin for $\Delta$ erg (mTn5gusA-pgfp22) and rifampicin for 22A-rif, for CFU determination.

\section{RESULTS AND DISCUSSION}

\section{Metabolome Analysis}

The methanolic extract of methanol-grown strain 22A cells was subjected to metabolome analysis with CE-TOF/MS. We found that among the major metabolites like serine, glutamine, lysine, arginine, and glycine, EGT was detected as a highly accumulated metabolite (Table S2). However, since the compound was not included in the HMT quantifiable compound library, its quantity was not determined. We did another trial but it was unsuccessful because the internal standard was not detected for unknown reasons. However, the EGT peak area that was identifiable by migration time and mass-to-charge ratio in the trial was the highest among all detected compounds, suggesting the high accumulation of EGT (data not shown).

\section{Extraction and Quantification of EGT}

EGT separation and quantification by HPLC was successfully established, as described in the Materials and Methods section. We used heat treatment $\left(94^{\circ} \mathrm{C}\right.$ for $\left.10 \mathrm{~min}\right)$ to effectively extract EGT from the cells without EGT decomposition. Additional heating of the remaining heat-treated cells also gave EGT, the amount of which was as small as $8 \%$ compared to that obtained by the first heating. We also varied the temperature of extraction $\left(40-100^{\circ} \mathrm{C}\right)$, and found that $60^{\circ} \mathrm{C}$ was sufficient to extract most EGT $\left(100 \%\right.$ EGT was extracted compared to $\left.100^{\circ} \mathrm{C}\right)$, and $50^{\circ} \mathrm{C}$ was insufficient (only $4.2 \%$ was extracted, data not shown). We used $94^{\circ} \mathrm{C}$ to ensure complete extraction for the following experiments. Heating of the aqueous EGT solution at $95^{\circ} \mathrm{C}$ did not result in apparent decomposition as monitored with HPLC (data not shown). Extraction with methanol resulted in a lowered EGT peak and the appearance of more other peaks in the HPLC chromatogram, suggesting that EGT was unstable in methanol. This might be the reason for the high variance of EGT concentrations detected in the metabolome analysis, where we used methanol for the extraction. We also quantified extracellular EGT in a concentrated spent medium (1-week-old $100 \mathrm{ml} \mathrm{MM}$ containing $0.5 \%$ methanol, re-dissolved in $1 \mathrm{ml}$ water after completely dried, done in triplicate), but EGT content in the samples was under the detection limit $(1 \mu \mathrm{M}$, injection volume to HPLC was $20 \mu \mathrm{l}$ ). Thus, extracellular EGT concentration was lower than $0.01 \mu \mathrm{M}$, suggesting that EGT is not secreted from the cells.

The simple method of heat treatment eases EGT extraction from the cells and reduces the downstream processing cost for EGT production. Although EGT has been reported to be secreted in Mycobacterium (Sao Emani et al., 2013), it was not secreted in Methylobacterium in this study. The difference in the physiological role of extracellular and intracellular EGT in different microorganisms remains unclear.

\section{Abundant Accumulation of EGT in Strain 22A}

In standard conditions (5 $\mathrm{ml} \mathrm{MM}$ containing 0.5\% methanol, 7 days, $28^{\circ} \mathrm{C}$ ), cell yield of strain $22 \mathrm{~A}$ was usually approximately $30 \mathrm{mg}$ (wet weight), equivalent to $6 \mathrm{mg}$ dry cell weight. The EGT yield was usually $10 \mu \mathrm{g}$ (1.6 mg EGT/g dry cell weight). 
The cell volume of strain $22 \mathrm{~A}$ was estimated to be $0.65 \mu \mathrm{m}^{3}$ (cell dimension was $2.24 \times 0.65 \mu \mathrm{m}$ bacilli form); therefore, the intracellular concentration of EGT was estimated to be approximately $183 \mathrm{mM}$. This intracellular concentration is much greater than the $0.3 \mu \mathrm{M}$ that was detected in fission yeast cells and the $1.6 \mathrm{mM}$ in the P3nmt1-egt $1^{+}$strain overexpressing the EGT synthetic gene (Pluskal et al., 2014). EGT productivity in strain $22 \mathrm{~A}$ in this condition was comparable to that in the most productive mushroom, Pleurotus osrteatus (oyster mushroom, $3.78 \mathrm{mg} / \mathrm{g}$ dry weight) (Woldegiorgis et al., 2014).

As shown in Figure 1, the EGT content in the methanolgrown cells was one of the highest among amino acids quantifiable with the amino acid analyzer, again suggesting the unusually high accumulation of EGT.

\section{M. aquaticum Strain 22A is One of the Most EGT-productive Strains Among Methylobacterium Type Strains}

We examined whether other Methylobacterium species also synthesize EGT. Methylobacterium type strains were grown on $0.5 \%$ methanol and intracellular EGT was quantified in the same condition. Through this preliminary screening, we found that most of the type strains synthesize EGT in a range of $0-100 \mu \mathrm{g} / \mathrm{g}$ wet weight cells (Figure S1). The productivity is widely distributed in Methylobacterium species and no bias was recognized in the relationship between their productivity and a phylogenetic tree based on their 16S rRNA gene sequences (data not shown). We selected five strains, four of whose genome information was available, and quantified EGT content with higher methanol concentration (3\%) in triplicate. As shown in Figure 2, M. oryzae DSM18207 was the most productive and strain $22 \mathrm{~A}$ was the second best. Since the genome information of M. oryzae was not available at that time (Kwak et al., 2014), we decided to use strain 22A for further analysis.

The genes for EGT synthesis have been found in many $\alpha$-proteobacteria (Seebeck, 2010) and indeed many species of Methylobacterium, Bradyrhizobium, Rhodopseudomonas, etc. harbor the genes. There might be a more productive strain in the class. Since many of them are plant-symbionts, it is tempting to speculate that the EGT found in plants (Ey et al., 2007) might be derived from such symbiotic $\alpha$-proteobacteria or that plants might also have a different biosynthetic pathway for EGT.

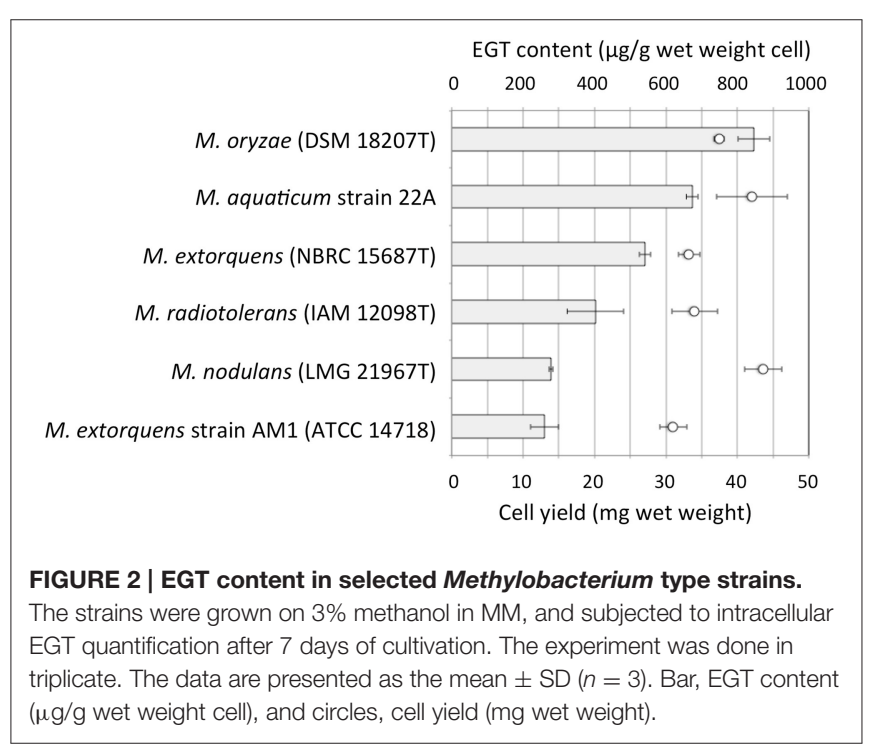

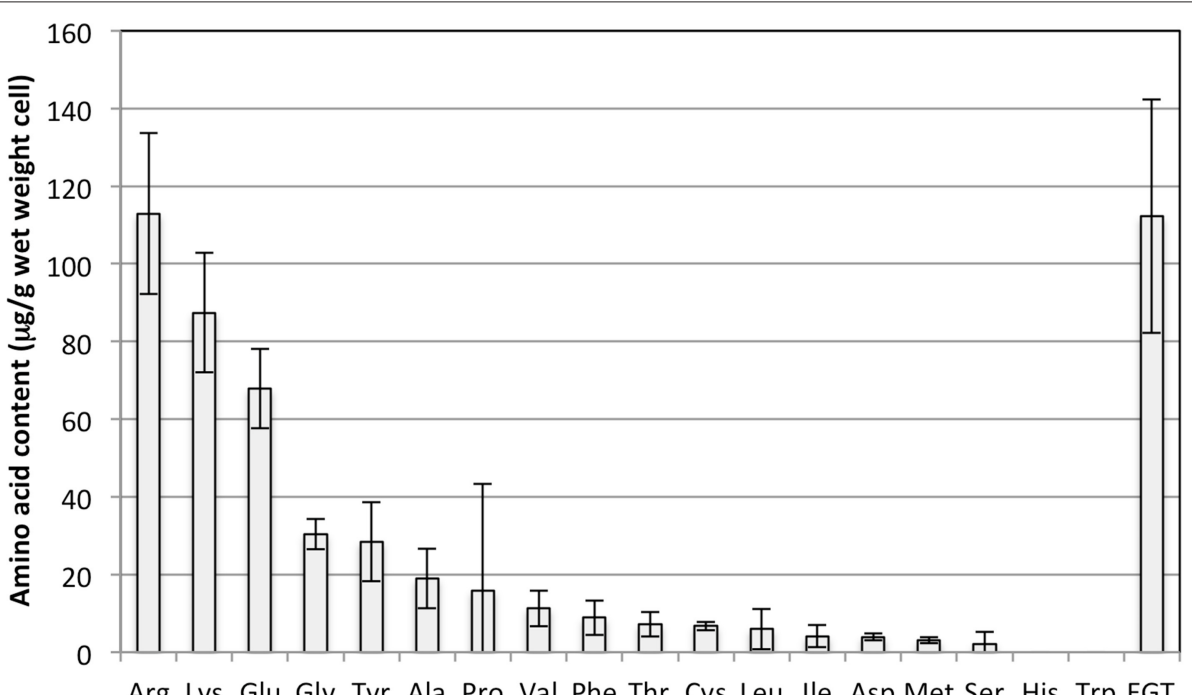

Amino acids

FIGURE 1 | Amino acid content in strain 22A cells grown on methanol (0.5\%) for $\mathbf{7}$ days. EGT was quantified by an HPLC and other amino acids were quantified using an amino acid analyzer. Glutamine and asparagine could not be analyzed by the analyzer. The data are presented as the mean \pm standard deviation (SD) $(n=3)$. 


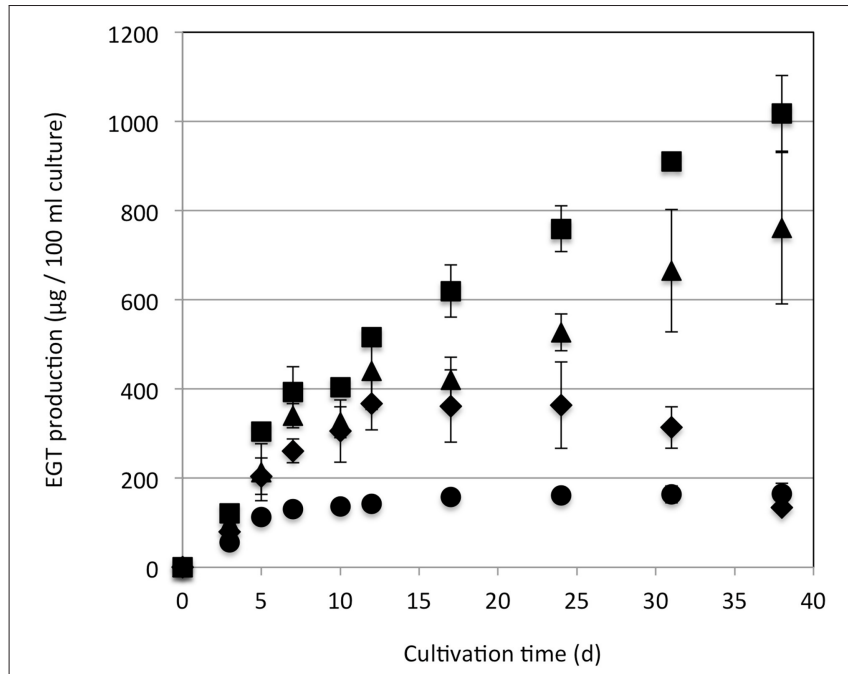

FIGURE 3 | EGT productivity of Methylobacterium sp. strain 22A. The strain was grown on $0.5 \%$ (circles), $1 \%$ (diamonds), $2 \%$ (squares), and $3 \%$ (triangles) methanol in a $100 \mathrm{ml} \mathrm{MM}$ for 38 days. The experiment was done in triplicate. The data are presented as the mean $\pm \operatorname{SD}(n=3)$.

Moreover, it has been reported that the EGT content in the orchid Gastrodia elata is correlated with the concentration of EGT in its symbiotic fungi, Armillaria mellea (Park et al., 2010).

\section{Optimization of EGT Production}

Strain 22A was cultured in MM containing 0.5\% methanol $(100 \mathrm{ml})$ containing different concentrations $(0.5,1,2$, and $3 \%)$ of methanol for 38 days and EGT productivity was monitored (Figure 3). Within a week, the cultures reached the stationary phase and OD600 increased only gradually afterwards (data not shown). Interestingly, the EGT amount in the culture did not increase after 7 days of cultivation on $0.5 \%$ methanol, but it increased when a higher concentration of methanol was used, whereas the OD600 did not increase. Strain 22A could grow in the presence of $3 \%$ methanol, but EGT productivity was best when $2 \%$ methanol was used. The EGT quantity in the MM containing $2 \%$ methanol reached $1000 \mu \mathrm{g} / 100 \mathrm{ml}$ culture $(1.2 \mathrm{mg} / \mathrm{g}$ wet weight, $6.3 \mathrm{mg} / \mathrm{g}$ dry weight) in 38 days, which overwhelms the productivity of $P$. ostreatus. EGT accumulated continuously until the late stationary phase, suggesting that EGT is a kind of secondary metabolite that is not involved directly in primary metabolism. Next, we tested other carbon sources, including ethanol, succinate, and glucose, and media of LB or Middlebrook 7H9 supplemented with methanol. EGT productivity was best when methanol was used (Figure 4). Succinate did not induce EGT production but glucose and ethanol did, suggesting that EGT production is not only induced by methanol. This result also suggested that EGT is not necessary for growth on methanol.

We tested other nitrogen sources at concentrations equivalent to $30 \mathrm{mM}$ nitrogen, and found that ammonium nitrate, ammonium chloride, and ammonium sulfate gave comparable cell yield and EGT. (Figure S2). Then we changed the

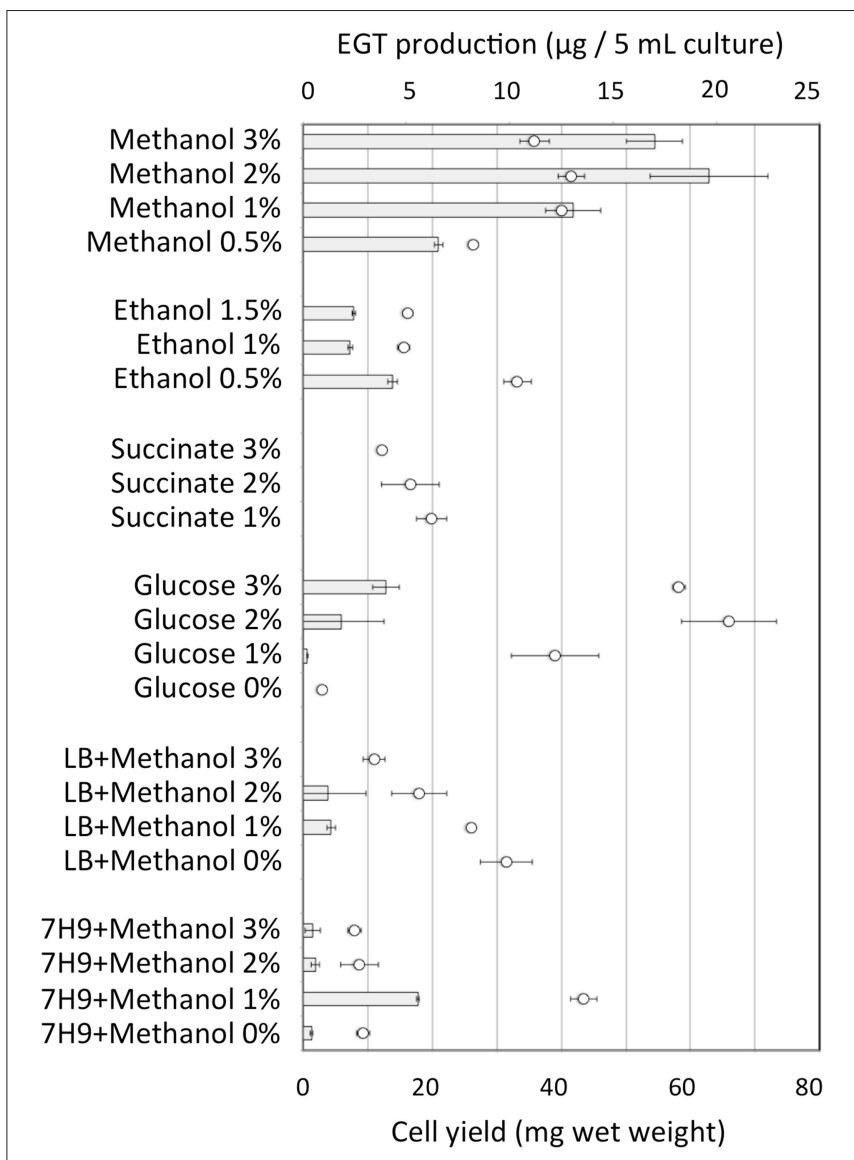

FIGURE 4 | EGT productivity of Methylobacterium sp. strain 22A grown on various carbon sources and media. The experiment was done in triplicate using $5 \mathrm{ml}$ media. The data are presented as the mean $\pm \mathrm{SD}(n=3)$. Bar, EGT production ( $\mu \mathrm{g} / 5 \mathrm{ml}$ culture), and circles, cell yield (mg wet weight).

nitrogen source (ammonium chloride) concentration under $0.5 \%$ methanol, and found that $0.4-1.2 \mathrm{~g} / \mathrm{l}$ was the best for production (Figure S3). Concentrations below 0.2 and above $2.0 \mathrm{~g} / \mathrm{l}$ resulted in poor cell growth. Compared to carbon sources, nitrogen sources were less effective for EGT production.

Histidine and cysteine are the precursors in the EGT biosynthesis pathway (Seebeck, 2010). The supplementation of histidine, cysteine, and their combination did not enhance EGT productivity significantly (Figure S4). However, the combination at $10 \mathrm{mM}$ doubled the productivity, but this concentration of amino acids is too high to be used as a supplement for largescale EGT production. It has been shown that EgtB is dependent on iron (II) for its catalysis (Seebeck, 2010). Thus, we varied the $\mathrm{FeSO}_{4}$ concentration $(0,10,17.3$ [original concentration], 100 , and $1000 \mu \mathrm{M})$ in $\mathrm{MM}$ containing $2 \%$ methanol. EGT production was comparable among $10-100 \mu \mathrm{M}$ and decreased in 0 and $1000 \mu \mathrm{M} \mathrm{FeSO}_{4}$ (data not shown). Methylobacterium species usually possess two methanol dehydrogenases encoded by MxaF and XoxF; the former is calcium-dependent and the latter is lanthanide-dependent (Hibi et al., 2011; Nakagawa et al., 2012; Keltjens et al., 2014). Thus, the effect of lanthanide 
supplementation on EGT production was investigated under different methanol concentrations. The EGT production and growth were negatively impacted by a higher concentration of lanthanide (Figure S5), suggesting that lanthanide is not effective at enhancing production.

Thus, through the preliminary optimization of cultivation conditions, we found that $2 \%$ methanol with His and Cys supplementation at $10 \mathrm{mM}$ was the best condition. Further optimization will be possible by testing other carbon sources and their mixtures, different temperatures, supplementation with other amino acids, and continuous cultivation with maintained $\mathrm{pH}$ and dissolved oxygen. Since EGT is considered to be a secondary metabolite, it may be necessary to mimic the condition of an aged culture to enhance the production, the factors of which are currently unknown.

\section{EGT Genes Found in Methylobacterium Species}

Genes homologous to egtABCDE in Mycobacterium (Seebeck, 2010; Jones et al., 2014) were found in strain 22A genome (Tani et al., 2015) by BLAST analysis, as well as in the complete genomes in other Methylobacterium species (Table S3). The overall shared identities based on amino acid sequences were 25-46\% compared to those in Mycobacterium species. EGT biosynthesis genes were present as single copies in the strain $22 \mathrm{~A}$ genome. egtB and egtD are found to be encoded tandemly in the largest plasmid (pMaq22A-1) in the strain 22A genome, whereas egt $A, C$, and $E$ are separately encoded in distant loci in the chromosome (Figure S6). It is reported that the clustered egt $A B C D E$ genes are found only in actinomycetes, and that egtB and egt $D$ are under strong selective pressure for genetic clustering (Jones et al., 2014). The cluster is also found in the genomes of $M$. radiotolerans JCM2831, $M$. nodulans ORS2060, M. extorquens AM1, and Methylobacterium sp. 4-46, but not in those of $M$. oryzae CBMB20 and M. populi Bj001. It is unknown whether their EGT productivity is dependent on the gene organization. However, since EgtD and EgtB catalyze the first two steps in EGT synthesis (Seebeck, 2010), the cluster may be important for efficient EGT synthesis. The conservation of five genes in Methylobacterium genomes supported their common ability to synthesize EGT in the genus.

\section{EGT Is Involved in Resistance to Heat Shock, UV Radiation, $\mathrm{H}_{2} \mathrm{O}_{2}$, and Fitness for Growth on Plants}

To clarify the function of EGT in Methylobacterium, we constructed an egtBD-deletion mutant $(\Delta e g t)$ via homologous recombination. Furthermore, functional egtBD were introduced into $\Delta e g t$ for complementation $(\Delta e g t \operatorname{Comp})$ and into the wild type as well for gene duplication (WTegtDup). EGT production in $\Delta e g t$ was completely abolished, and $\Delta e g t \operatorname{Comp}$ recovered EGT production with higher production than the wild type (Figure 5). Duplication of egtBD resulted in increased synthesis of EGT compared to the wild type. These results indicated that egtBD genes are indeed involved in EGT synthesis and that the synthetic pathway would be the same as the one for Mycobacterium

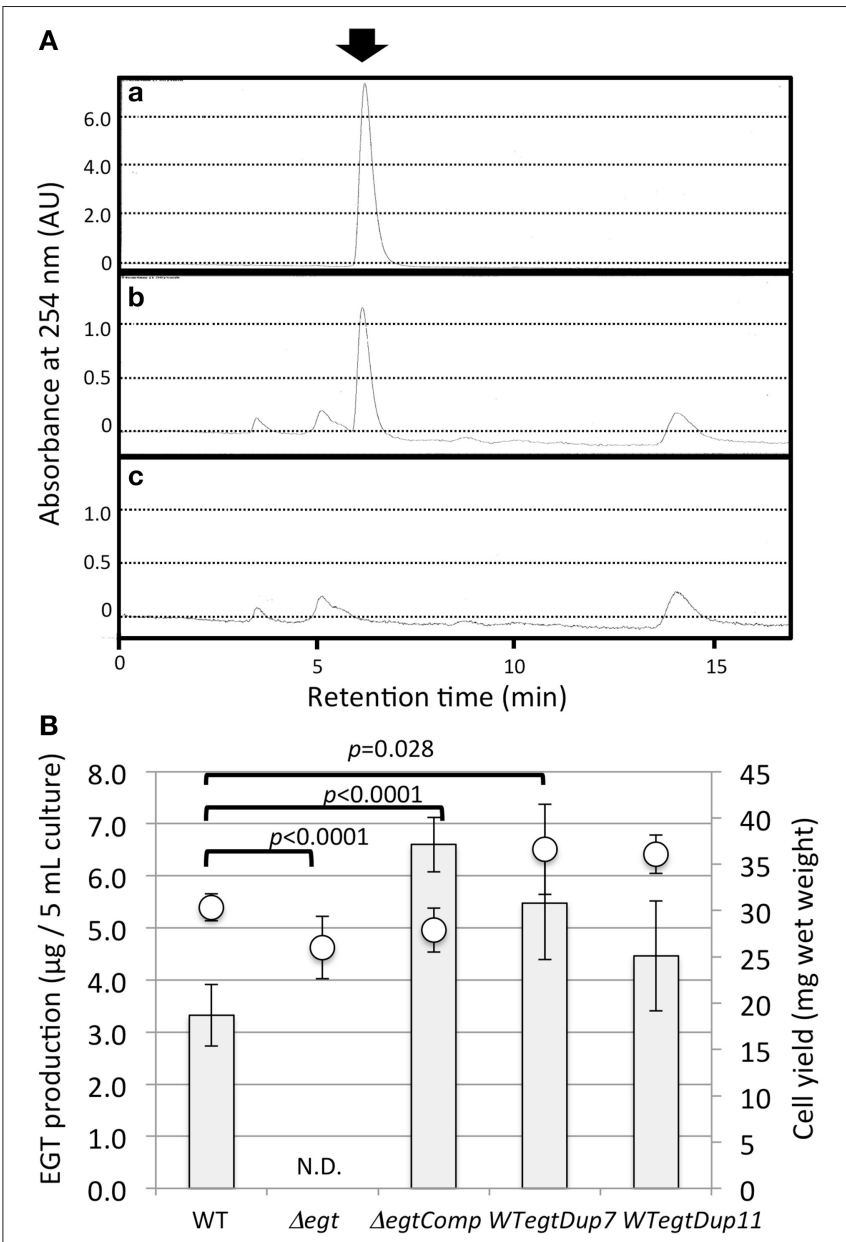

FIGURE 5 | (A) HPLC chromatograms of (a) standard EGT (100 $\mu \mathrm{M})$, (b) extract of strain 22A wild-type cells, and (c) extract of $\Delta$ egt cells. The arrow indicates the EGT peak detected at $6.2 \mathrm{~min}$. The HPLC analysis condition is described in the text. (B) EGT productivity of $\Delta$ egt, $\Delta$ egtComp, and WTegtDup cells. Two independent transformants of WTegtDup isolates were tested. The cells were grown on $0.5 \%$ methanol in MM medium for 1 week and subjected to EGT quantification. Bar, EGT production ( $\mu \mathrm{g} / 5 \mathrm{ml}$ culture), and circles, cell yield (mg wet weight). The data are presented as the mean $\pm \operatorname{SD}(n=5)$. $p$-values were generated by analysis of variance (ANOVA) using the Dunnett's multiple comparison test with the control (the wild type) for EGT production.

species. In addition, it was possible to enhance the production by duplicating the genes.

The mutant $\Delta$ egt showed a slightly increased growth rate and cell yield on methanol (Figure S7), which was more evident with higher methanol concentration, indicating that EGT is not required for methylotrophic growth. When they were grown on methanol at elevated temperature $\left(31^{\circ} \mathrm{C}\right.$ and $\left.34^{\circ} \mathrm{C}\right)$, slightly increased growth of $\Delta e g t$ was still observed (data not shown). The reason for the better growth would be the biological cost for EGT production. Interestingly, the growth on glucose was not affected by the mutagenesis at all (data not shown), which was congruent with the low productivity of EGT on glucose (Figure 4). 
$\Delta$ egt was more sensitive to heat shock than the wild type (Figure 6A). In addition to heat shock, UV irradiation severely reduced the viability of $\Delta$ egt (Figure 6B). Exposure of $100 \mu \mathrm{M}$ EGT solution to UV in the same condition resulted in a marked decrease in the EGT peak ( 35 and $87 \%$ decrease in 5 and $30 \mathrm{~min}$, respectively) and a concomitant increased peak at $10.3 \mathrm{~min}$ (unknown compound) in the HPLC chromatogram, suggesting that EGT is degraded by UV (data not shown). Furthermore, when methanol-grown 22A cells were exposed to UV in the same condition for 5, 30, and $60 \mathrm{~min}$, the intracellular EGT content decreased to $31,0.5$, and $0 \%$, respectively (data not shown). These results indicated that EGT protects the cells for survival under UV. These results prompted us to see the effect of sunlight on the mutant survival. It is known that the strongest UV, UV-C $(100-290 \mathrm{~nm})$, does not reach to the ground due to the ozone layer. The UV lamp $(254 \mathrm{~nm})$ we used for the assay belongs to UV-C. Within the total UV reaching the ground, more than $95 \%$ is UV-A (320-400 nm), and less than 5\% is UV-B (290-320 nm) that can cause DNA damage and kill bacteria. It is also known that glass is transparent to UV-A but not to UV-B (Duarte et al., 2009), and that cellophane is partly transparent to UV-B (Auras et al., 2004). We found that sunlight through the glass killed the wild type and the mutant at a comparable rate, and that sunlight through the cellophane killed $\Delta$ egt more efficiently than the wild type (Figure 6C). We also observed that the mutant formed colonies much slower than the wild type after the exposure (data not shown). These results strongly suggested that EGT protects the cells against sunlight, to which the Methylobacterium cells are exposed in the phyllosphere.

Interestingly, $\Delta$ egt showed higher resistance to $\mathrm{H}_{2} \mathrm{O}_{2}$ (Figure 6D), but no phenotype in sensitivity to other oxidative stress of methylglyoxal and diamide (Figures 6E,F). It is known that Methylobacterium species synthesize glutathione in addition to EGT, and that Mycobacterium species synthesize EGT and mycothiol as sulfur-containing antioxidants. In Mycobacterium smegmatis, mycothiol-deficient mutants showed elevated levels of EGT (Ta et al., 2011), whereas mycothiol level was unchanged in EGT mutant in M. smegmatis (Sao Emani et al., 2013). In contrast, egtA mutant in Streptomyces coelicolor A3(2), which still produces a decreased amount of EGT, produces five-fold more mycothiol compared to the wild type (Nakajima et al., 2015). Thus, in actinobacteria, a defect in one antioxidant may be compensated by an increased amount of another antioxidant. These facts led us to quantify glutathione in $\Delta$ egt. The glutathione content (reduced form) in $\Delta$ egt grown on methanol was $2.29 \mu \mathrm{g} / 5 \mathrm{ml}$ culture, while that in the wild type was $2.05 \mu \mathrm{g} / 5 \mathrm{ml}$ culture, showing a statistically insignificant increase ( $n=3$ each, $p=0.11$, Student's $t$-test). The oxidized form was not detected. At this time, we cannot attribute the increased $\mathrm{H}_{2} \mathrm{O}_{2}$ resistance of the mutant to increased glutathione content. In the case of egtA mutant in S. coelicolor A3(2) (Nakajima et al., 2015), intracellular EGT content was severely reduced but the secreted EGT was not, and the mutant showed high susceptibility to $\mathrm{H}_{2} \mathrm{O}_{2}$. Thus, the resistance to $\mathrm{H}_{2} \mathrm{O}_{2}$ cannot be explained
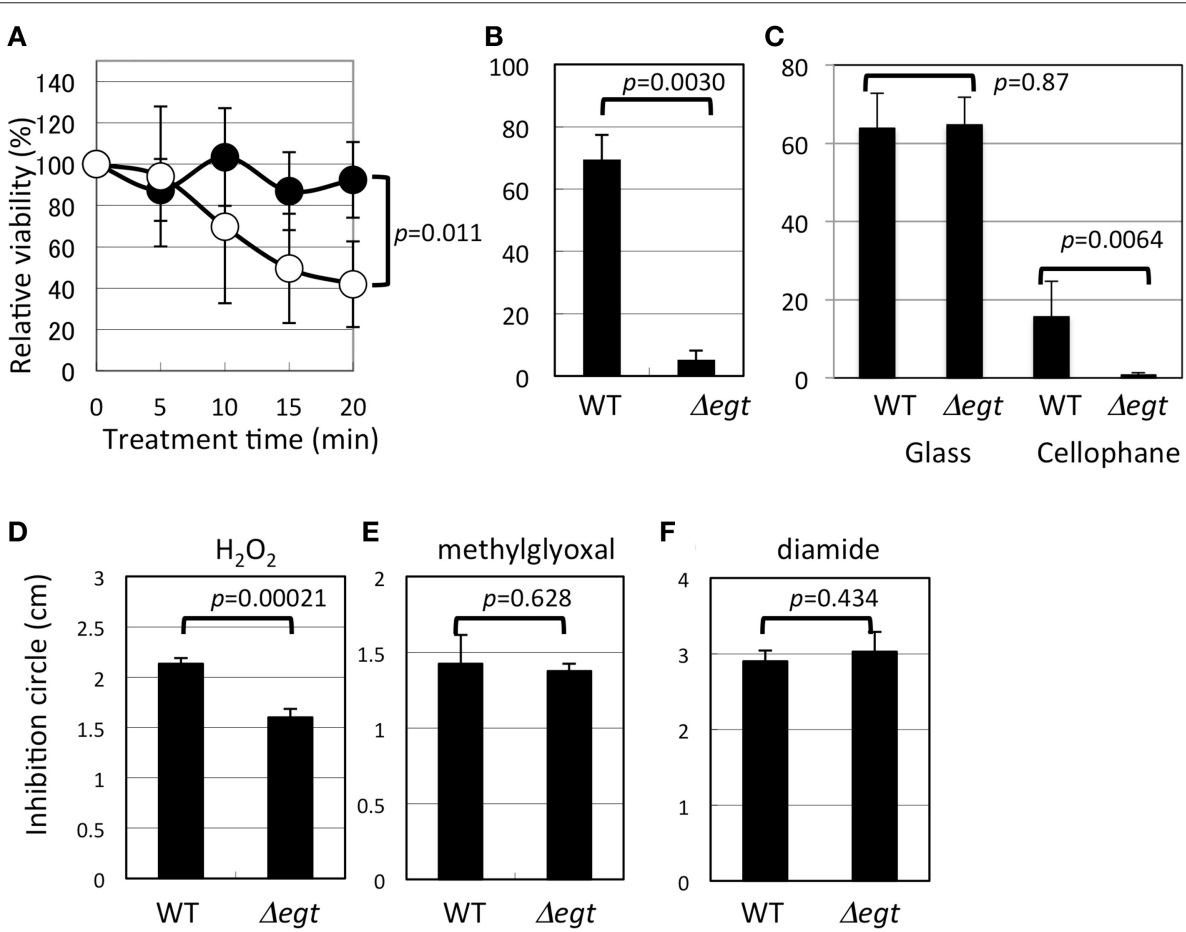

FIGURE 6 | Phenotypic characterization of $\boldsymbol{\Delta}$ egt mutant. (A) Heat shock assay at $46^{\circ} \mathrm{C}$ (closed symbols, wild type, and open symbols, $\Delta$ egt); (B) UV (253 $\mathrm{nm}$ ) resistance assay; (C) sunlight-resistance assay; (D-F), disk diffusion assay using hydrogen peroxide, methylglyoxal, and diamide, respectively. All experiments except (C) that was done in quintuplicate, were done in quadruplicate. The data are presented as the mean \pm SD $(n=4)$. Experimental conditions are written in the text. 
solely by intracellular EGT content for different bacteria, and it is possible that the strain $22 \mathrm{~A}$ may contain other antioxidant molecules that compensate for the defect in EGT. A recent paper described the essential role of EGT and mycothiol in lincomycin A synthesis in Streptomyces lincolnensis (Zhao et al., 2015). Thus, it is also possible that Methylobacterium species utilize EGT for synthesis of other unknown secondary metabolites.

Taken together, these results indicate that EGT contributes to resistance to heat shock and UV stress. The antioxidant activity of EGT has been shown in many reports (Cheah and Halliwell, 2012). EGT reacts with the hydroxyl radical at a diffusioncontrolled rate, but not readily with $\mathrm{H}_{2} \mathrm{O}_{2}$ and $\mathrm{O}_{2}^{-}$. Furthermore, EGT can repair the guanyl radical, which is a product of DNA ionization (Asmus et al., 1996). This could be the reason why $\Delta$ egt showed susceptibility to UV irradiation that elicits DNA damage.

Formaldehyde is the central metabolite in methylotrophy and it is not known whether EGT reacts with formaldehyde. Glutathione, on the other hand, is known to spontaneously react with formaldehyde to form S-hydroxymethylglutahione in Paracoccus denitrificans (Goenrich et al., 2002). In formaldehyde dissimilation in Methylobacterium, formaldehyde reacts with dephosphotetrahydromethanopterin ( $\left.\mathrm{d}_{4} \mathrm{HMPT}\right)$ either spontaneously or enzymatically by formaldehyde-activating enzyme (Fae). In assimilation, methylene tetrahydrofolate $\left(\mathrm{H}_{4} \mathrm{~F}\right)$, as the $\mathrm{C} 1$ unit for the serine cycle, is produced either spontaneously by the condensation of formaldehyde and $\mathrm{H}_{4} \mathrm{~F}$ or enzymatically through the $\mathrm{H}_{4} \mathrm{MPT}$-dependent pathway (Ochsner et al., 2015). Thus, in Methylobacterium, glutathione is not involved in formaldehyde assimilation and dissimilation. However, recalling the case of $P$. denitrificans, we examined whether EGT reacts with formaldehyde. We mixed $1 \mathrm{M}$ formaldehyde and $100 \mu \mathrm{M}$ EGT, incubated it for 5-24 h at room temperature, and then examined the HPLC pattern. We did not observe any change in peak height or retention time, suggesting that EGT does not spontaneously react with formaldehyde in vitro. This result again indicates that EGT is not directly involved in methylotrophy.

Next, we examined the growth of $\Delta$ egt in the phyllosphere. The growth of $\Delta e g t(\mathrm{mTn} 5 g u s A-p g f p 22)$ was slightly decreased compared to 22A-rif when they were independently grown on A. thaliana leaves (Figure 7). When they were co-inoculated in competitive conditions, the lesser growth of 22A-rif was observed. As previously shown in Figure S7, the biological cost of EGT synthesis might be the reason for the lesser growth of the wild type. In this experimental condition, we used fluorescent lamps, which usually contain little UV. In addition, plastic petri dishes diminish UV. Thus, the experiment was performed in UV-free conditions.

\section{Exogenous Supplementation of EGT Is Not Effective in the Growth of Wild Type and Plant}

Supplementation of EGT did not enhance the growth of the wild type on methanol, and was rather inhibitory (Figure S8A). The cause of this effect is unknown, but it is possible that EGT may inhibit some periplasmic enzymes, to which many of those involved in methanol oxidation belong. It is also unknown whether the cells incorporate EGT via transporters, since EGT is believed to be membrane-impermeable. We found proteins homologous to human OCTN1 (BAA23356.1) encoded in Methylobacterium genomes with less than 27\% identity. This should be further examined to determine their involvement in EGT uptake.

The growth of $A$. thaliana on $1 / 2$ MS agar was not affected by the exogenous supplementation of EGT at the tested concentrations (Figure S8B). Since EGT is exclusively accumulated in the cells and is not secreted extracellularly, exogenous EGT may not occur in Methylobacterium-plant

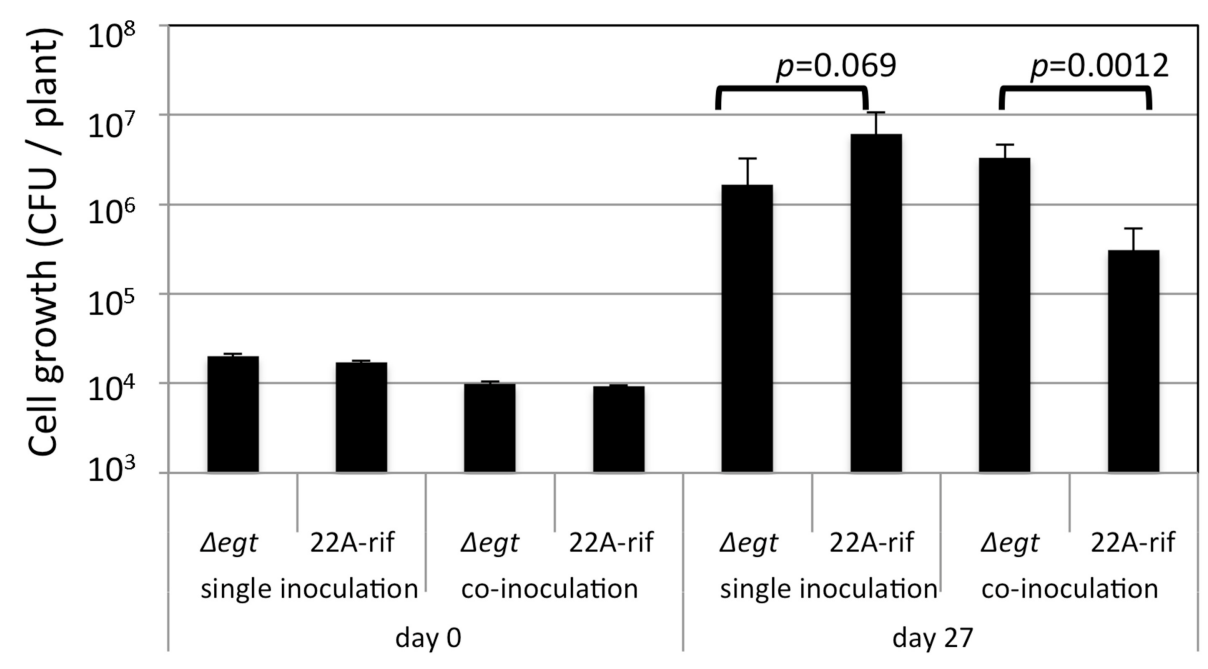

FIGURE 7 | Growth of strain 22A-rif and $\Delta$ egt inoculated onto $\boldsymbol{A}$. thaliana seeds. After 27 days of inoculation, the shoots were sampled and subjected to CFU determination using selective media. The data are presented as mean $\pm \operatorname{SD}(n=5)$. 
interactions. Lysed bacterial cells may serve as an EGT source for plants, but there have been no reports on the existence of an active EGT transporter in plants. There are many OCTN1 homologs encoded in the genomes of a wide variety of plants, including cucumber, chickpea, wheat, barley, grapevine, potato, Physcomitrella, and so on, with less than $33 \%$ identity. It is currently unknown whether any of them is involved in EGT transport in plants. Since EGT is also found in plants, there must be an EGT transporter in plants; however, the biological role of EGT in plants remains uninvestigated.

In conclusion, we found that Methylobacterium species are able to synthesize abundant EGT. EGT is exclusively accumulated in the cells and is not secreted extracellularly. Using one of the most productive strains, we optimized the culture conditions mainly with respect to carbon and nitrogen sources and supplements. The production level overwhelms that of the most productive mushroom. High cell density cultivation is reported for Methylobacterium species, which can achieve as much as $100 \mathrm{~g}$ dry weight cells per liter (Bourque et al., 1995). These established cultivation techniques and the genetic manipulation we showed by gene duplication would be very useful in terms of improving production. Since pure EGT is expensive due to limited sources, we are interested in the further development of more efficient fermentative production using Methylobacterium species and methanol as a cheap feedstock. We identified EGT synthesis genes in strain 22A and generated an EGT synthesis mutant. EGT synthesis was found to be nonessential for methylotrophy. We also found that the mutant was susceptible to UV and heat shock. Importantly, the mutant is more susceptible to sunlight than the wild type. As inhabitants on the plant surface, resistance to UV is essential for their survival. Herein, we provided evidence of the involvement of EGT in the resistance. Since EGT was produced by many Methylobacterium type strains, EGT might be a ubiquitous UV-protectant for the genus.

\section{REFERENCES}

Abanda-Nkpwatt, D., Müsch, M., Tschiersch, J., Boettner, M., and Schwab, W. (2006). Molecular interaction between Methylobacterium extorquens and seedlings: growth promotion, methanol consumption, and localization of the methanol emission site. J. Exp. Bot. 57, 4025-4032. doi: 10.1093/jxb/erl173

Asmus, K. D., Bensasson, R. V., Bernier, J. L., Houssin, R., and Land, E. J. (1996). One-electron oxidation of ergothioneine and analogues investigated by pulse radiolysis: redox reaction involving ergothioneine and vitamin C. Biochem. J. 315(Pt 2), 625-629. doi: 10.1042/bj3150625

Auras, R., Harte, B., and Selke, S. (2004). An overview of polylactides as packaging materials. Macromol. Biosci. 4, 835-864. doi: 10.1002/mabi.200400043

Bazela, K., Solyga-Zurek, A., Debowska, R., Rogiewicz, K., Bartnik, E., and Eris, I. (2014). L-Ergothioneine protects skin cells against UV-induced damage-a preliminary study. Cosmetics 1, 51-60. doi: 10.3390/cosmetics1010051

Bélanger, L., Figueira, M. M., Bourque, D., Morel, L., Béland, M., Laramée, L., et al. (2004). Production of heterologous protein by Methylobacterium extorquens in high cell density fermentation. FEMS Microbiol. Lett. 231, 197-204. doi: 10.1016/S0378-1097(03)00956-X

Bourque, D., Pomerleau, Y., and Groleau, D. (1995). High-cell-density production of poly- $\beta$-hydroxybutyrate (PHB) from methanol by Methylobacterium extorquens: production of high-molecular-mass PHB. Appl. Microbiol. Biotechnol. 44, 367-376. doi: 10.1007/BF00169931
Interestingly, EGT is a precursor for the synthesis of selenoneine, which has a selenoketone structure instead of thiocarbonyl in EGT (Yamashita et al., 2010). Selenoneine is reported to have three orders of magnitude stronger radical scavenging activity against 1-diphenyl-2-picrylhydrazyl than EGT (Yamashita and Yamashita, 2010). The synthesis of selenoneine is suggested to be dependent on selenocysteine (Pluskal et al., 2014). Further study is necessary to examine the possible potential of selenoneine synthesis and its role in Methylobacterium species. In addition, an EGT-degrading enzyme called ergothionase has been reported for E. coli (Wolff, 1962) and Burkholderia (Muramatsu et al., 2013). We found the homologous gene in the 22A genome, the mutant of which may be more productive.

\section{AUTHOR CONTRIBUTIONS}

KA, SM, and AT designed the experiments. KA, SM, YF, FF, and AT performed the experiments. KA, SM, FF, and AT wrote the manuscript.

\section{ACKNOWLEDGMENTS}

This work is supported, in part, by the Japan Science and Technology Agency (JST) A-Step feasibility study stage (\#AS251Z00826N), the Noda Institute for Scientific Research, and the Advanced Low Carbon Technology Research and Development Program (ALCA), JST.

\section{SUPPLEMENTARY MATERIAL}

The Supplementary Material for this article can be found online at: http://journal.frontiersin.org/article/10.3389/fmicb. 2015.01185

Cheah, I. K., and Halliwell, B. (2012). Ergothioneine; antioxidant potential, physiological function and role in disease. Biochim. Biophys. Acta 1822, 784-893. doi: 10.1016/j.bbadis.2011.09.017

Chinnadurai, C., Balachandar, D., and Sundaram, S. P. (2009). Characterization of 1-aminocyclopropane-1-carboxylate deaminase producing methylobacteria from phyllosphere of rice and their role in ethylene regulation. World J. Microbiol. Biotechnol. 25, 1403-1411. doi: 10.1007/s11274-009-0027-1

Chistoserdova, L. (2011). Modularity of methylotrophy, revisited. Environ. Microbiol. 13, 2603-2622. doi: 10.1111/j.1462-2920.2011.02464.x

Delmotte, N., Knief, C., Chaffron, S., Innerebner, G., Roschitzki, B., Schlapbach, R., et al. (2009). Community proteogenomics reveals insights into the physiology of phyllosphere bacteria. Proc. Natl. Acad. Sci. U.S.A. 106, 16428-16433. doi: 10.1073/pnas.0905240106

Duarte, I., Rotter, A., Malvestiti, A., and Silva, M. (2009). The role of glass as a barrier against the transmission of ultraviolet radiation: an experimental study. Photodermatol. Photoimmunol. Photomed. 25, 181-184. doi: 10.1111/j.16000781.2009.00434.x

Dubost, N. J., Beelman, R. B., Peterson, D., and Royse, D. J. (2006). Identification and quantification of ergothioneine in cultivated mushrooms by liquid chromatography-mass spectroscopy. Int. J. Med. Mushr. 8, 215-222. doi: 10.1615/IntJMedMushr.v8.i3.30

Ey, J., Schömig, E., and Taubert, D. (2007). Dietary sources and antioxidant effects of ergothioneine. J. Agric. Food Chem. 55, 6466-6474. doi: 10.1021/jf071328f 
Fahey, R. C. (2001). Novel thiols of prokaryotes. Ann. Rev. Microbiol. 55, 333-356. doi: 10.1146/annurev.micro.55.1.333

Fall, R., and Benson, A. A. (1996). Leaf methanol - the simplest natural product from plants. Trends Plant Sci. 1, 296-301. doi: 10.1016/S1360-1385(96)88175-0

Goenrich, M., Bartoschek, S., Hagemeier, C. H., Griesinger, C., and Vorholt, J. A. (2002). A glutathione-dependent formaldehyde-activating enzyme (Gfa) from Paracoccus denitrificans detected and purified via two-dimensional proton exchange NMR spectroscopy. J. Biol. Chem. 277, 3069-3072. doi: 10.1074/jbc.C100579200

Gourion, B., Rossignol, M., and Vorholt, J. A. (2006). A proteomic study of Methylobacterium extorquens reveals a response regulator essential for epiphytic growth. Proc. Natl. Acad. Sci. U.S.A. 103, 13186-13191. doi: 10.1073/pnas.0603530103

Grigat, S., Harlfinger, S., Pal, S., Striebinger, R., Golz, S., Geerts, A., et al. (2007). Probing the substrate specificity of the ergothioneine transporter with methimazole, hercynine, and organic cations. Biochem. Pharmacol. 74, 309-316. doi: 10.1016/j.bcp.2007.04.015

Gründemann, D., Harlfinger, S., Golz, S., Geerts, A., Lazar, A., Berkels, R., et al. (2005). Discovery of the ergothioneine transporter. Proc. Natl. Acad. Sci. U.S.A. 102, 5256-5261. doi: 10.1073/pnas.0408624102

Guenther, A., Hewitt, C. N., Erickson, D., Fall, R., Geron, C., Graedel, T., et al. (1995). A global model of natural volatile organic compound emissions. J. Geophys. Res. 100, 8873-8892. doi: 10.1029/94jd02950

Hibi, Y., Asai, K., Arafuka, H., Hamajima, M., Iwama, T., and Kawai, K. (2011). Molecular structure of $\mathrm{La}^{3+}$-induced methanol dehydrogenase-like protein in Methylobacterium radiotolerans. J. Biosci. Bioeng. 111, 547-549. doi: 10.1016/j.jbiosc.2010.12.017

Iguchi, H., Sato, I., Yurimoto, H., and Sakai, Y. (2013). Stress resistance and C1 metabolism involved in plant colonization of a methanotroph Methylosinus sp. B4S. Arch. Microbiol. 195, 717-726. doi: 10.1007/s00203-013-0922-6

Ito, T., Kato, M., Tsuchida, H., Harada, E., Niwa, T., and Osawa, T. (2011). Ergothioneine as an anti-oxidative/anti-inflammatory component in several edible mushrooms. Food Sci. Technol. Res. 17, 103-110. doi: 10.3136/fstr.17.103

Ivanova, E. G., Doronina, N. V., Shepelyakovskaya, A. O., Laman, A. G., Brovko, F. A., and Trotsenko, Y. A. (2000). Facultative and obligate aerobic Methylobacteria synthesize cytokinins. Microbiology 69, 646-651. doi: 10.1023/A:1026693805653

Jones, G. W., Doyle, S., and Fitzpatrick, D. A. (2014). The evolutionary history of the genes involved in the biosynthesis of the antioxidant ergothioneine. Gene 549, 161-170. doi: 10.1016/j.gene.2014.07.065

Jourand, P., Renier, A., Rapior, S., Miana de Faria, S., Prin, Y., Galiana, A., et al. (2005). Role of methylotrophy during symbiosis between Methylobacterium nodulans and Crotalaria podocarpa. Mol. Plant Microbe Interact. 18, 1061-1068. doi: 10.1094/MPMI-18-1061

Keltjens, J. T., Pol, A., Reimann, J., and Op den Camp, H. J. M. (2014). PQQdependent methanol dehydrogenases: rare-earth elements make a difference. Appl. Microbiol. Biotechnol. 98, 6163-6183. doi: 10.1007/s00253-0145766-8

Knief, C., Delmotte, N., Chaffron, S., Stark, M., Innerebner, G., Wassmann, R., et al. (2011). Metaproteogenomic analysis of microbial communities in the phyllosphere and rhizosphere of rice. ISME J. 6, 1378-1390. doi: 10.1038/ismej.2011.192

Koenig, R. L., Morris, R. O., and Polacco, J. C. (2002). tRNA is the source of low-level trans-zeatin production in Methylobacterium spp. J. Bacteriol. 184, 1832-1842. doi: 10.1128/JB.184.7.1832-1842.2002

Kwak, M.-J., Jeong, H., Madhaiyan, M., Lee, Y., Sa, T.-M., Oh, T. K., et al. (2014). Genome information of Methylobacterium oryzae, a plantprobiotic methylotroph in the phyllosphere. PLOS ONE 9:e106704. doi: 10.1371/journal.pone.0106704

Madhaiyan, M., Selvaraj, P., Jeounghyun, R., and Tongmin, S. (2006). Regulation of ethylene levels in canola (Brassica campestris) by 1-aminocyclopropane-1carboxylate deaminase-containing Methylobacterium fujisawaense. Planta 224, 268-278. doi: 10.1007/s00425-005-0211-y

Madhaiyan, M., Poonguzhali, S., and Sa, T. (2007). Characterization of 1-aminocyclopropane-1-carboxylate (ACC) deaminase containing Methylobacterium oryzae and interactions with auxins and ACC regulation of ethylene in canola (Brassica campestris). Planta 226, 867-876. doi: 10.1007/s00425-007-0532-0
Mann, T., and Leone, E. (1953). Studies on the metabolism of semen. 8. Ergothioneine as a normal constituent of boar seminal plasma. Purification and crystallization. Site of formation and function. Biochem. J. 53, 140-148. doi: $10.1042 / \mathrm{bj0530140}$

Middlebrook, G., and Cohn, M. L. (1958). Bacteriology of tuberculosis: laboratory methods. Am. J. Public Health Nations. Health 48, 844-853. doi: 10.2105/AJPH.48.7.844

Morris, C. E., and Kinkel, L. L. (2002). "Fifty years of phylosphere microbiology: significant contributions to research in related fields," in Phyllosphere Microbiology, eds E. S. Lindow, E. I. Hecht-Poinar, and V. J. Elliott (St. Paul, MN: APS Press), 365-375.

Muramatsu, H., Matsuo, H., Okada, N., Ueda, M., Yamamoto, H., Kato, S.-I., et al. (2013). Characterization of ergothionase from Burkholderia sp. HME13 and its application to enzymatic quantification of ergothioneine. Appl. Microbiol. Biotechnol. 97, 5389-5400. doi: 10.1007/s00253-012-4442-0

Nakagawa, T., Mitsui, R., Tani, A., Sasa, K., and Tashiro, S. (2012). A catalytic role of XoxF1 as $\mathrm{La}^{3+}$-dependent methanol dehydrogenase in Methylobacterium extorquens strain AM1. PLoS ONE 7:e50480. doi: 10.1371/journal.pone.0050480

Nakajima, S., Satoh, Y., Yanashima, K., Matsui, T., and Dairi, T. (2015). Ergothioneine protects Streptomyces coelicolor A3(2) from oxidative stresses. J. Biosci. Bioeng. 120, 294-298. doi: 10.1016/j.jbiosc.2015.01.013

Ochsner, A. M., Sonntag, F., Buchhaupt, M., Schrader, J., and Vorholt, J. A. (2015). Methylobacterium extorquens: methylotrophy and biotechnological applications. Appl. Microbiol. Biotechnol. 99, 517-534. doi: 10.1007/s00253014-6240-3

Park, E.-J., Lee, W. Y., Kim, S. T., Ahn, J. K., and Bae, E. K. (2010). Ergothioneine accumulation in a medicinal plant Gastrodia elata. J. Med. Plants Res. 4, 1141-1147. doi: 10.5897/JMPR10.184

Paul, B. D., and Snyder, S. H. (2010). The unusual amino acid L-ergothioneine is a physiologic cytoprotectant. Cell Death Differ. 17, 1134-1140. doi: 10.1038/cdd.2009.163

Pfeiffer, C., Bauer, T., Surek, B., Schömig, E., and Gründemann, D. (2011). Cyanobacteria produce high levels of ergothioneine. Food Chem. 129, 1766-1769. doi: 10.1016/j.foodchem.2011.06.047

Pluskal, T., Ueno, M., and Yanagida, M. (2014). Genetic and metabolomic dissection of the ergothioneine and selenoneine biosynthetic pathway in the fission yeast, $S$. pombe, and construction of an overproduction system. PLoS ONE 9:e97774. doi: 10.1371/journal.pone.0097774

Sao Emani, C., Williams, M. J., Wiid, I. J., Hiten, N. F., Viljoen, A. J., Pietersen, R.-D. D., et al. (2013). Ergothioneine is a secreted antioxidant in Mycobacterium smegmatis. Antimicrob. Agents Chemother. 57, 3202-3207. doi: 10.1128/AAC.02572-12

Schäfer, A., Tauch, A., Jäger, W., Kalinowski, J., Thierbach, G., and Pühler, A. (1994). Small mobilizable multi-purpose cloning vectors derived from the Escherichia coli plasmids pK18 and pK19: selection of defined deletions in the chromosome of Corynebacterium glutamicum. Gene 145, 69-73. doi: 10.1016/0378-1119(94)90324-7

Schauer, S., and Kutschera, U. (2011). A novel growth-promoting microbe, Methylobacterium funariae sp. nov., isolated from the leaf surface of a common moss. Plant Signal Behav. 6, 510-515. doi: 10.4161/psb.6.4.14335

Schrader, J., Schilling, M., Holtmann, D., Sell, D., Filho, M. V., Marx, A., et al. (2009). Methanol-based industrial biotechnology: current status and future perspectives of methylotrophic bacteria. Trends Biotechnol. 27, 107-115. doi: 10.1016/j.tibtech.2008.10.009

Seebeck, F. P. (2010). In vitro reconstitution of Mycobacterial ergothioneine biosynthesis. J. Am. Chem. Soc. 132, 6632-6633. doi: 10.1021/ja101721e

Šmejkalová, H., Erb, T. J., and Fuchs, G. (2010). Methanol assimilation in Methylobacterium extorquens AM1: demonstration of all enzymes and their regulation. PLoS ONE 5:e13001. doi: 10.1371/journal.pone.0013001

Soga, T., Ohashi, Y., Ueno, Y., Naraoka, H., Tomita, M., and Nishioka, T. (2003). Quantitative metabolome analysis using capillary electrophoresis mass spectrometry. J. Proteome Res. 2, 488-494. doi: 10.1021/pr0 $34020 \mathrm{~m}$

Ta, P., Buchmeier, N., Newton, G. L., Rawat, M., and Fahey, R. C. (2011). Organic hydroperoxide resistance protein and ergothioneine compensate for loss of mycothiol in Mycobacterium smegmatis mutants. J. Bacteriol. 193, 1981-1990. doi: 10.1128/JB.01402-10 
Tani, A., Takai, Y., Suzukawa, I., Akita, M., Murase, H., and Kimbara, K. (2012). Practical application of methanol-mediated mutualistic symbiosis between Methylobacterium species and a roof greening moss, Racomitrium japonicum. PLoS ONE 7:e33800. doi: 10.1371/journal.pone.0033800

Tani, A., Ogura, Y., Hayashi, T., and Kimbara, K. (2015). Complete genome sequence of Methylobacterium aquaticum strain 22A, isolated from Racomitrium japonicum moss. Genome Announc 3:e00266-15. doi: 10.1128/genomeA.00266-15

Vorholt, J. A. (2012). Microbial life in the phyllosphere. Nat. Rev. Microbiol. 10, 828-840. doi: 10.1038/nrmicro2910

Vuilleumier, S., Chistoserdova, L., Lee, M.-C., Bringel, F., Lajus, A., Zhou, Y., et al. (2009). Methylobacterium genome sequences: a reference blueprint to investigate microbial metabolism of $\mathrm{C} 1$ compounds from natural and industrial sources. PLOS ONE 4:e5584. doi: 10.1371/journal.pone.00 05584

Woldegiorgis, A. Z., Abate, D., Haki, G. D., and Ziegler, G. R. (2014). Antioxidant property of edible mushrooms collected from Ethiopia. Food Chem. 157, 30-36. doi: 10.1016/j.foodchem.2014.02.014

Wolff, J. B. (1962). Ergothionase from Escherichia coli. J. Biol. Chem. 237, 874-881.

Xi, C., Lambrecht, M., and Vanderleyden, J. (1999). Bi-functional $g f p$-and $g u s A$ containing mini-Tn5 transposon derivatives for combined gene expression and bacterial localization studies. J. Microbiol. Methods 35, 85-83. doi: 10.1016/S0167-7012(98)00103-1
Yamashita, Y., Yabu, T., and Yamashita, M. (2010). Discovery of the strong antioxidant selenoneine in tuna and selenium redox metabolism. World J. Biol. Chem. 1, 144-150. doi: 10.4331/wjbc.v1.i5.144

Yamashita, Y., and Yamashita, M. (2010). Identification of a novel seleniumcontaining compound, selenoneine, as the predominant chemical form of organic selenium in the blood of bluefin tuna. J. Biol. Chem. 285, 18134-18138. doi: 10.1074/jbc.C110.106377

Zhao, Q., Wang, M., Xu, D., Zhang, Q., and Liu, W. (2015). Metabolic coupling of two small-molecule thiols programs the biosynthesis of lincomycin A. Nature $518,115-119$.

Conflict of Interest Statement: The authors declare that this research was conducted in the absence of any commercial or financial relationships that could be construed as a potential conflict of interest. AT is listed as an inventor on a pending patent application (JP P2014-259232, filing date: December 22, 2014) on the use of Methylobacterium species for EGT production.

Copyright (C) 2015 Alamgir, Masuda, Fujitani, Fukuda and Tani. This is an openaccess article distributed under the terms of the Creative Commons Attribution License (CC BY). The use, distribution or reproduction in other forums is permitted, provided the original author(s) or licensor are credited and that the original publication in this journal is cited, in accordance with accepted academic practice. No use, distribution or reproduction is permitted which does not comply with these terms. 